Fumio Asato MD PhD, A kifumi Kanai $M D$

\title{
Sensory blockade of S3 dermatome prevents pain during bladder catheterization
}

Purpose: We often encounter patients who do not complain of pain on undergoing invasive urogenital or rectal procedures, despite incomplete epidural blockade of sacral cutaneous sensation. To clarify whether or not urethral pain is blocked faster than sacral cutaneous sensation during lumbar epidural anesthesia, we investigated the correlation between occurrence of urethral pain and loss of cold sensation in the S1-3 dermatomes.

M ethods: In 46 gynecological patients, G roup $A(n=22)$ received $15 \mathrm{ml}$ of $2 \%$ mepivacaine via an epidural catheter inserted cephaladly. Group $B(n=24)$ received $5 \mathrm{ml}$ of $2 \%$ mepivacaine directly in the epidural needle directed caudally and $10 \mathrm{ml}$ of $2 \%$ mepivacaine via the epidural catheter inserted cephaladly. A Foley catheter was inserted into the urethra 30 min after the injection.

Results: U rethral pain, which was defined as a pained facial expression and/or complaint of pain, was observed in seven patients in Group $A$, and none in Group $B$. The caudad level of epidural blockade was significantly lower in patients without urethral pain $(\mathrm{S} 3$, median) than with urethral pain ( $L 4)(P<0.05)$. In 39 patients without urethral pain, $19(49 \%)$ experienced loss of cold sensation in the S1 dermatome, $27(69 \%)$ in the S2 and $38(97 \%)$ in the S3 25 min after the injection.

C onclusion: Blockade of urethral visceral pain often occurs before complete sacral somatosensory blockade, and S3 somatosensory blockade is the important sacral level as an indicator of successful urethral sensory blockade.

Objectif : II arrive souvent que des patients ne ressentent aucune douleur lors d'interventions urogénitales ou rectales effractives malgré le blocage péridural incomplet de la sensibilité cutanée au niveau du sacrum. Pour vérifier si la douleur urétrale est bloquée plus vite ou non que la sensibilité cutanée sacrée pendant l'anesthésie péridurale lombaire, on a cherché la corrélation entre l'occurrence de douleur urétrale et la perte de la sensibilité au froid au niveau des dermatomes de S1-3.

Méthode: Des 46 patientes de gynécologie, un groupe $A(n=22)$ a reçu $15 \mathrm{ml}$ de mépivacaïne à $2 \%$ au moyen d'un cathéter péridural inséré en direction céphalique. Le groupe $B(n=24)$ a reçu $5 \mathrm{ml}$ de mépivacaïne à $2 \%$ par l'aiguille péridurale directement, insérée en direction caudale, et $10 \mathrm{ml}$ de mépivacaïne à $2 \%$ par le cathéter péridural placé en direction céphalique. Un cathéter Foley a été inséré dans l'urètre 30 min après l'injection.

R ésultats: La douleur urétrale, exprimée par une expression faciale de douleur et/ou une plainte verbale, a été observée chez sept patientes du groupe $A$, mais aucune du groupe $B$. Le niveau caudal du blocage péridural a été significativement plus bas chez les patientes sans douleur urétrale (S3, médiane) que chez celles qui ont éprouvé de la douleur $(L 4)(P<0,05)$. Chez 39 patientes sans douleur uré trale, $19(49 \%)$ ont connu une perte de la sensibilité au froid à S1, $27(69 \%)$ à S2 et $38(97 \%)$ à S3, 25 min après l'injection.

C onclusion : Le blocage de la douleur viscérale urétrale survient souvent avant le blocage somesthésique sacré complet. Le bloc somesthésique à S3 sert ainsi d'indicateur d'un bloc sensitif urétral réussi.

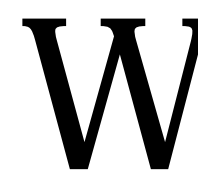

ITH lumbar epidural anesthesia, cutaneous analgesia at the S1 dermatome takes longer to develop than at the S2-3 dermatomes because of the differences in nerve root size, even with sufficient spread of local anesthetic in the sacral area. ${ }^{1}$ Of the 40 patients in our previous study, only 15 (38\%) experienced loss of cold sensation in the S1 dermatome with 33 (83\%) reporting loss in the S3 dermatome. ${ }^{2}$ $\mathrm{H}$ owever, even in cases of incomplete epidural blockade of the sacral nerves, we often encounter patients who do not complain of unpleasant sensations or pain upon undergoing invasive urogenital or rectal procedures that are expected to cause pain. Clinical experiences like these suggest that urethral or rectal pain is blocked faster than the cutaneous cold sensation in the sacral nerves in the early stages of lumbar epidural anesthesia. To clarify this issue, we investigated the correlation between the occurrence of urethral viscer-

From the D epartment of A nesthesiology, Kitasato U niversity School of M edicine, Kanagawa, Japan.

A ddress correspondence to: Dr. Fumio Asato, D epartment of Anesthesiology, Kitasato U niversity School of M edicine, Kanagawa 228-

8555, Japan. Phone: 81-42-778-8616; Fax: 81-42-778-8441; E-mail: fasato@med.kitasato-u.ac.jp

A ccepted for publication D ecember 5, 2000 
TAB LE Comparison of cutaneous sensory blockade between patients presenting signs of urethral pain (Group U P-Positive) and patients not presenting signs of urethral pain (Group U P-N egative) upon urinary bladder catheterization

\begin{tabular}{|c|c|c|c|c|}
\hline & \multicolumn{2}{|c|}{ Group U P-N $(n=39)$} & \multicolumn{2}{|c|}{ Group U P-P $(n=7)$} \\
\hline & A fter $15 \mathrm{~min}$ & A fter $25 \mathrm{~min}$ & A fter $15 \mathrm{~min}$ & After $25 \mathrm{~min}$ \\
\hline \multicolumn{5}{|c|}{$\begin{array}{l}\text { Extent of loss of cutaneous } \\
\text { cold sensation after injection }\end{array}$} \\
\hline $\begin{array}{l}\text { Cephalad level } \\
\text { Caudad level }\end{array}$ & $\begin{array}{l}\text { T } 8 \text { (T 1-L 2) } \\
\text { S3 (L 1-S3)* }\end{array}$ & $\begin{array}{l}\text { T7 (C 7-L2) } \\
\text { S3 (L4-S3)* }\end{array}$ & $\begin{array}{l}\text { T7 (T2-T12) } \\
\text { L3 (L2-L4) }\end{array}$ & $\begin{array}{l}\text { T3 (T2-T 12) } \\
\text { L4 (L3-S3) }\end{array}$ \\
\hline \multicolumn{5}{|l|}{$\begin{array}{l}N \text { umber of patients with } \\
\text { blockade in the sacral } \\
\text { dermatomes }\end{array}$} \\
\hline S1 dermatome & $10(26 \%) *$ & $19(49 \%) *$ & 0 & 0 \\
\hline $\mathrm{S} 2$ dermatome & $18(46 \%) *$ & $27(69 \%) *$ & 0 & 0 \\
\hline S3 dermatome & $23(59 \%) *$ & $38(97 \%)^{*}$ & $1(14 \%)$ & $1(14 \%)$ \\
\hline
\end{tabular}

*P $<0.05$. M ann-Whitney U test, compared to Group U P-P

Cephalad and caudad levels are expressed as median (range)

al pain (pained facial expression or complaint of pain in response to insertion of a Foley catheter into the urethra) and the loss of cold sensation in the S1-3 dermatomes. In addition, we also investigated whether combined injections through the epidural needle and catheter affect the presence or absence of urethral pain, when compared to catheter injection alone.

\section{M ethods}

Fifty gynecological patients without neurological disease were enrolled in this study after obtaining informed consent from all patients and institutional approval for the study. All patients were premedicated with atropine (0.25-0.5 mg) and hydroxyzine (25-50 mg) 45 min before the procedure. Epidural puncture was performed in the left lateral decubitus position using the loss of resistance technique with a saline containing syringe attached to a 17 gauge Tuohy needle with the bevel directed cephalad via a midline approach at the L 2-3 or L 3-4 interspace. T wo methods were used to inject a total volume of $15 \mathrm{ml}$ of $2 \%$ mepivacaine: the catheter only technique (Group A) and our previously published catheter and needle method (Group B, outlined below). ${ }^{2}$ Patients were randomly assigned to either group. In Group A ( 25 patients), the epidural catheter was advanced $5 \mathrm{~cm}$ cephalad into the epidural space and fixed in position: after careful aspiration $3 \mathrm{ml}$ of $2 \%$ mepivacaine were injected. The patient was turned supine, and the remaining $12 \mathrm{ml}$ of $2 \%$ mepivacaine were injected through the catheter three to five minutes after the first injection. In Group B (25 patients), the bevel of the epidural needle was directed in a caudad direction and after careful aspiration, $5 \mathrm{ml}$ of $2 \%$ mepivacaine were injected rapidly. The bevel was then rotated in the cephalad direction and an epidural catheter introduced. The remaining $10 \mathrm{ml}$ of $2 \%$ mepivacaine were injected through the catheter three to five minutes after the first injection.

The spread of loss of cutaneous cold sensation was determined using a swab of cotton wool soaked in absolute alcohol 15 and 25 min after the first injection. Special attention was paid to cold sensation in the S1-3 dermatomes. We did not examine the S4 and S5 dermatomes because cutaneous cold sensation in the S3 dermatome is blocked just as quickly as in both $\mathrm{S} 4$ and S5 dermatomes. ${ }^{3}$ The anesthesiologist who examined the sensory level was unaware of which injection method had been used. In cases of failure or unilateral epidural blockade, the epidural anesthesia procedure was repeated and patients were excluded from the study. The remaining patients were placed in the lithotomy position, and a Foley catheter was inserted through the urethra into the bladder by a gynecologist $30 \mathrm{~min}$ after the first injection. A pained facial expression (a grimace or eyes closed tightly) and/ or complaint of pain in response to insertion of the Foley catheter were defined as urethral pain. The anesthesiologist who observed the response to catheterization had no prior knowledge of either the extent of loss of cold sensation or the technique used for epidural blockade. Statistical analysis was performed using the non-paired test and $M$ ann-Whitney $U$ test. Statistical significance was established at the $P<0.05$ level.

\section{Results}

There were four patients who had block failure (one patient in Group A) or unilateral epidural blockade (three patients: two in Group A and one in Group B) and who were excluded from the study. The remain- 
ing 46 patients ( 22 in Group A and 24 in Group B) were investigated.

$U$ rethral pain in response to insertion of a Foley catheter was observed in seven patients in Group $A$ $(n=22)$, and none in Group $B(n=24)$. Thus, 39 patients were devoid of signs of urethral pain (Group UP$\mathrm{N}$ egative) and seven presented signs of urethral pain (Group U P-Positive). Age, height and weight did not differ significantly between the two groups (age: U P-N , $47.4 \pm 15.6 \mathrm{yr}$, mean \pm SD ; U P-P, $44.0 \pm 10.8$, height: $155.3 \pm 7.0 \mathrm{~cm}$, mean \pm SD; $154.7 \pm 3.9$, weight: 53.3 $\pm 7.3 \mathrm{~kg}$, mean $\pm \mathrm{SD} ; 51.3 \pm 6.7$, respectively).

$\mathrm{N}$ o significant difference was seen in the cephalad level of loss of cutaneous cold sensation between Groups UP- N and UP-P at 15 and 25 min after epidural injection (Table). H owever, at both 15 and $25 \mathrm{~min}$, the caudad level of loss of cutaneous cold sensation was significantly lower in Group UP-N than that in Group UP-P; at $15 \mathrm{~min}$ : U P-N, S3 (L 1-S3) [median, (range)]; U P-P, L3 (L2-L4), at 25 min: U PN, S3 (L4-S3); UP-P, L4 (L3-S3), ( $P<0.05)$. In Group U P-P, at both 15 and 25 min after injection only one patient experienced loss of cold sensation in the S3 dermatome on the right side, suggesting that the local anesthetic did not extend to the sacral area in this group. In contrast, in Group U P-N , ten patients (26\%) experienced loss of cold sensation in the S1 dermatome, 18 (46\%) in the S2 dermatome and 23 (59\%) in the S3 dermatome $15 \mathrm{~min}$ after injection. Moreover, $25 \mathrm{~min}$ after injection, the number of patients experiencing loss of cold sensation increased to 19 patients (49\%) in the S1 dermatome, 27 (69\%) in S2 and $38(97 \%)$ in S3.

\section{Discussion}

$O$ ur results indicate that loss of cold sensation observed in the $\mathrm{S} 3$ dermatome correlates with the absence of pain during catheterization of the urinary bladder. Based on these findings, there are two possible roles of the sacral nerves in urethral pain transmission.

First, this implies that visceral afferent fibres, which convey urethral pain, are predominantly located in the third sacral nerve, since $97 \%$ of the patients who had loss of cold sensation in the third sacral dermatome did not show any pain response $25 \mathrm{~min}$ after injection. Interestingly, Kiesswetter ${ }^{4}$ has reported that, in humans, urethral electrosensitivity remains within the normal range if the S3 segment is intact although there may be damage to higher segments. This is in agreement with our findings.

Sensory innervation of the urethra consists of the hypogastric (T11-L2), pelvic (S2-4) and pudendal nerves (S2-4). ${ }^{5,6}$ In animals, two different types of sensory afferents from the urethra have been reported; myelinated afferent fibres in the pelvic nerve which respond to movements of the urethral catheter, ${ }^{7}$ and unmyelinated afferent fibres in the sacral ventral root which respond to distension of the urethra, ${ }^{8}$ and both are thought to be responsible for urethral pain. In humans, the sensory and motor innervation of the urinary bladder has been reported in the management of detrusor reflex and pain in patients with neurogenic bladder, ${ }^{9,10}$ however, the transmission of urethral pain remains unclear. $O$ ur results suggest that urethral pain which responds to insertion of a Foley catheter is transmitted through the pelvic or pudendal nerves (S2-4) and not through the hypogastric nerve (T 11-L2), as six of the seven patients with urethral pain had no epidural blockade in the sacral dermatomes and five of the 39 patients without urethral pain had no epidural blockade between the cephalad levels T11 and L2. Interestingly, $M C M$ ahon ${ }^{11}$ reviewed visceral pain, and described that all bladder sensations including pain can be signalled by pelvic nerve afferents, although many textbooks state that the urinary bladder receives a dual afferent innervation with both the sympathetic nerves (the hypogastric and lumbar splanchnic) and the parasympathetic nerves (the pelvic nerve). M cM ahon's findings support our results despite the difference in visceral organ between the urinary bladder and urethra.

Second, our results suggest that differential blockade between visceral and cutaneous sensation can occur, with the result that the visceral afferent fibres in the sacral nerves, which transmit urethral pain, may be blocked faster than the cutaneous cold afferent fibres. This could be supported by the fact that visceral structures probably have an innervation density of less than $1 \%$ of that found in skin. ${ }^{11} \mathrm{~N}$ amely, the number of urethral pain fibres is so small, compared to that of cutaneous fibres, that urethral pain could be blocked completely before developing complete blockade of cutaneous sensations.

Differential epidural blockade with local anesthetics has focused mainly on somatic nerves, and is utilized clinically for acute or chronic pain management to provide analgesia without motor weakness. Based on our results indicating the presence of differential blockade between cutaneous and visceral pain sensations, it may be possible, in future studies, to find drugs which could block only visceral pain transmission while other visceral functions remain normal. Recently, "spatial summation" has reappeared as one of the theories explaining how differential blockade develops. ${ }^{12,13}$ This theory states that one can perceive pain sensation when the area of stimulation is large 
enough to activate the nerve, even if the degree of single stimulation is lower than the pain threshold. $\mathrm{N}$ amely, incomplete blockade of cutaneous cold sensation dose not necessarily indicate that urethral pain afferent fibres have not been blocked. Based on this theory, it remains unclear, in our results, whether the first and second sacral nerves contribute to urethral pain transmission. Further studies concerning these issues are necessary in humans and animals.

The method used to inject the local anesthetic described herein completely blocks urethral pain 25 min after injection, consequently shortening the wait before the start of surgery. The disadvantage of the method is that the epidural needle must be rotated in the epidural space thereby increasing the risk of dural puncture or unintentional subarachnoid catheter insertion. The extent of this risk is controversial, ${ }^{14,15}$ however, there has been no case of dural puncture with this method in our clinical practice.

Rapid epidural injection through the needle is known to increase the pressure in the epidural space and cause transient back pain or discomfort in most patients. ${ }^{16} \mathrm{H}$ owever, this was not a serious problem in our patients. We postulate that the small volume of local anesthetic injected $(5 \mathrm{ml}$ ) was not sufficient to increase the pressure in the epidural space and cause discomfort.

We conclude that S3 so matosensory blockade is the important sacral level indicative of successful urethral sensory blockade. S3 somatosensory blockade is achieved more rapidly when local anesthetic is injected both through the needle and through the epidural catheter.

\section{Acknowledgment}

The authors thank to Dr. Stephen H Butler, Associate Professor, Department of Anesthesiology and Multidisciplinary Pain Center, U niversity of Washington, Seattle, USA, for his advice in editing this manuscript.

\section{References}

1 Galindo A, H ernandez J, Benavides O, Ortegon De M unoz S, Bonica JJ. Q uality of spinal extradural anaesthesia: the influence of spinal nerve root diameter. $\mathrm{Br}$ J Anaesth 1975; 47: 41-7.

2 A sato F, H irakawa N, A raki K, et al. A technique for obtaining successful sacral spread with continuous lumbar epidural anesthesia. Anesth Analg 1990; 70 : 662-4.

3 A xelsson K, N ydahl P-A, Philipson L, Larsson P. M otor and sensory blockade after epidural injection of mepivacaine, bupivacaine and etidocaine - a double-blind study. Anesth Analg 1989; 69: 739-47.
4 K iesswetter $H$. M ucosal sensory threshold of urinary bladder and urethra measured electrically. U rol Int 1977; 32: 437-48.

5 Elhilali MM, Winfield H N. Genitourinary pain. In: Wall PD, M elzack R (Eds.). Textbook of pain.

Edinburgh: Churchill Livingstone, 1994: 643-9.

6 Wesselmann U, Burnett A L, H einberg LJ. The urogenital and rectal pain syndromes. Pain 1997; 73: 269-94.

7 BahnsE, $\mathrm{H}$ alsband U, Jänig W. Responses of sacral visceral afferents from the lower urinary tract, colon and anus to mechanical stimulation. Pflügers Arch 1987; 410: 296-303.

8 Clifton GL, Coggeshall RE, VanceWH, WillisWD. Receptive fields of unmyelinated ventral root afferent fibres in the cat. J Physiol 1976; 256: 573-600.

9 R ockswold GL, Bradley WE, Chou SN. Differential sacral rhizotomy in the treatment of neurogenic bladder dysfunction. Preliminary report of six cases. J N eurosurg 1973; 38: 748-54.

10 R ockswold GL, Bradley WE, Chou SN. Effect of sacral nerve blocks on the function of the urinary bladder in humans. J N eurosurg 1974; 40: 83-9.

$11 \mathrm{M} \mathrm{cM}$ ahon SB, D mitrieva N, Koltzenburg M. Visceral pain. Br J Anaesth 1995; 75: 132-44.

12 Fink BR. M echanisms of differential axial blockade in epidural and subarachnoid anesthesia. Anesthesiology 1989; 70: 851-8.

13 Jaffe R A, R owe M A. Differential nerve block. D irect measurements on individual myelinated and unmyelinated dorsal root axons. Anesthesiology 1996; 84: 1455-64.

14 M oore DC. Rotating the epidural needle: a cautionwhere is the clinical proof? (Letter). Anesth Analg 1994; 79: 810.

15 Bromage PR. Rotation of the epidural needle: a caution (Letter). Anesth Analg 1995; 81: 209-10.

16 Erdemir H A, Soper LE, Sweet R B. Studies of factors affecting peridural anesthesia. Anesth Analg 1965; 44: 400-4. 